\title{
Acute Budd Chiari Syndrome
}

\author{
AFMH UDDIN ${ }^{\mathrm{a}}$, M WARESHUZZAMAN ${ }^{\mathrm{b}}$, RK BANIK ${ }^{\mathrm{c}}$, SK SAHA ${ }^{\mathrm{c}}, \mathrm{NC}^{\mathrm{N}} \mathrm{NATH}^{\mathrm{c}}$, \\ BC SHIL $^{\mathrm{d}}$, MO FARUQUE ${ }^{\mathrm{d}}$, SC DHAR ${ }^{\mathrm{e}}$
}

\begin{abstract}
Summary:
Budd-Chiari syndrome (BCS) is a rare disease in population characterized by hepatic venous outflow obstruction at a site that may vary from the level of the small hepatic veins up to the junction of the inferior vena cava with the right atrium. Here we presented a case of 35 year old male who presented with abdominal pain, abdominal distension and leg oedema. Subsequent physical examination, laboratory data, abdominal ultrasonography and duplex
\end{abstract}

\section{Introduction:}

Budd-Chiari syndrome (BCS) is a rare disease in population. Prevalence remains largely unknown but estimates range between 1/50,000 and 1/100,000. BCS is characterized by hepatic venous outflow obstruction located at the level of the small hepatic veins up to the junction of the inferior vena cava with the right atrium 1 . The occlusion of the veins, mostly caused by a thrombus leads to increased sinusoidal pressure and ischaemic necrosis.

Various forms of presentation and course of the disease have been observed, ranging from the asymptomatic ones to the fulminant hepatic failure. Clinical symptoms of BCS include fever, abdominal pain, ascites, oedema, gastrointestinal bleeding and hepatic encehalopathy ${ }^{2}$.

a. Dr. AFM Helal Uddin, Registrar, Department of Gastroenterology, Sir Salimullah Medical College \& Mitford Hospital, Dhaka.

b. Dr. M Wareshuzzaman, Assistant Registrar, Department of Gastroenterology, Sir Salimullah Medical College \& Mitford Hospital, Dhaka.

c. Dr. R K Banik, Dr. S K Saha, Dr. NC Nath, Assistant Professor, Department of Gastroenterology, Sir Salimullah Medical College \& Mitford Hospital, Dhaka.

d. Dr. BC Shil, Dr. M O Faruque, Associate Professor, Department of Gastroenterology, Sir Salimullah Medical College \& Mitford Hospital, Dhaka.

e. Professor SC Dhar, Department of Gastroenterology, Sir Salimullah Medical College \& Mitford Hospital, Dhaka.

Address of Correspondence: Professor Swapan Chandra Dhar, Professor and Head, Department of Gastroenterology, SSMC \& Mitford hospital, Mobile No: 01713019015, E-mail address :swapan_gastro@yahoo.com

Received: 23 December, 2012

Accepted: 10 June, 2013 study all confirmed the diagnosis of BCS with Protein C, protein $S$, and antithrombin III deficiency . But we were unable to detect whether these factor deficiency were primary or secondary. Genetic study may be used to elucidate the cause. Whether primary or secondary, standard protocol should be used to treat Budd Chiari syndrome with these factor deficiency.

(J Banagladesh Coll Phys Surg 2013; 31: 223-226)

Presentation is not the key to understand the duration of the disease and the BCS course can be steadily progressive, or marked by exacerbations and remissions. The disease can run a long insidious course, or a short period of prodrome followed by a rapid downhill course 2,3,4. Presentation and manifestation varies and BCS should always be considered in a young or middle aged patient with portal hypertension of unknown origin .

Obstruction of the hepatic venous outflow tract may be the result of an endoluminal venous lesion like thrombosis or web or may be due to malignant tumor or a parasitic mass invading the lumen or from extrinsic compression by a neighboring tumor (abscesses, cysts, benign or malignant solid tumors) ${ }^{4}$. Modern imaging techniques allow easy recognition of these associated lesions. The site of obstruction is in general easily determined through non-invasive imaging (Dopplerultrasound, magnetic resonance (MRI), computed tomography or conventional venography.

The disease may be lethal within 3 years of symptoms occurrence in majority of untreated patients, however modern treatment allows to achieve almost 90\% 5-year survival rate. There are no randomized clinical trials comparing various treatment options, however anticoagulation therapy remains the only available therapeutic option for every patient and early initiation is recommended regardless of whether an underlying prothrombic disorder has been detected or not ${ }^{5}$.

Protein $\mathrm{C}$ and protein $\mathrm{S}$ are vitamin K-dependent factors that together act as an anticoagulant, and antithrombin III is a plasma protein that inhibits several activated factors in the coagulation cascade. Deficiency of these factor may be hereditary causing BCS or acquired after 
development of BCS due to some inflammatory condition . Diagnosis may be confirmed by assessment of these factors in blood. Although Level $<50 \%$ of normal usually indicates hereditary deficiency sometimes it is necessary to assess parents of index case for diagnosis of hereditary deficiency . If it is not possible siblings of index case should be assessed for these factors deficiency. Recent usage of gene sequencing in the elucidation of anticoagulant protein gene mutation may now provide the potential to determine whether such anticoagulant deficiencies in BCS are truly hereditary or not.

For symptomatic patients, anticoagulation should be combined with diuretics or paracentesis for ascites and with pharmacological or endoscopic therapy when there is a history of bleeding due to portal hypertension. Patients with ascites, variceal bleeding or signs of liver failure should be followed closely. Those who do not improve or develop severe or recurrent complications despite medical treatment should be considered for stenting, placement of transjugular intrahepatic portosystemic shunt (TIPS) or surgical portosystemic shunting ${ }^{6}$. Orthotopic liver transplantation should be considered as effective treatment for rapidly progressive Budd-Chiari syndrome after failure of conventional treatment or portosystemic shunting ${ }^{7,8}$. Early mortality is related mainly to infections and late mortality to recurrent Budd-Chiari syndrome or thrombosis of the vena cava or portal vein, despite anticoagulation. Morbidity is related mainly to portal and arterial thrombosis, and hemorrhage under anticoagulant therapy. Since most patients with BCS exhibit important risk factors for thrombosis, anticoagulation is probably best continued after transplantation.

Here we are presenting a case of Acute Budd-Chiari Syndrome with Protein C Protein S and Anti thrombin III deficiency. Although in 2007 Rahman et al. reported a case of BCS due to IVC webs this is probably the first case of BCS in Bangladesh with Protein C, Protein S and Antithrombin III deficiency .

Case presentation:

A 35 year old male patient was admitted in SSMC \& Mitford hospital with the complaints of anorexia, yellow coloration of urine , abdominal pain, respiratory distress, abdominal distension and swelling of the legs for two weeks. Patient gave no previous history of jaundice, blood transfusion, joint pain, redness of eye ,oral ulcer ,weakness of limbs or any limb swelling, bleeding from gum, nose or rectum ,haematemesis or melaena. He also gave no history of intravenous drug abuse. He was non diabetic and gave no History tuberculosis . There was no family history of liver disease or haematological disease. Physical examination revealed that the patient had mild dyspnoea, moderate jaundice and pale skin .Neck veins were engorged and there was edema of legs. There was no clubbing, cyanosis ,leuconychia ,palmar erythema ,parotid swelling ,gynaecomastia or spider naevi. Examination of the abdomen revealed engorged veins , an enlarged and tender liver and ascites but there was no splenomegaly or testicular atrophy . Other systemic examination findings were normal.

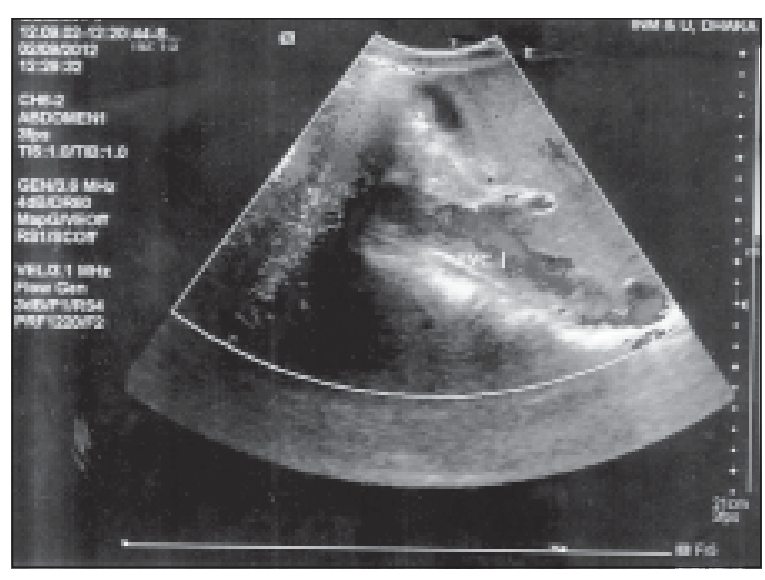

Fig :1

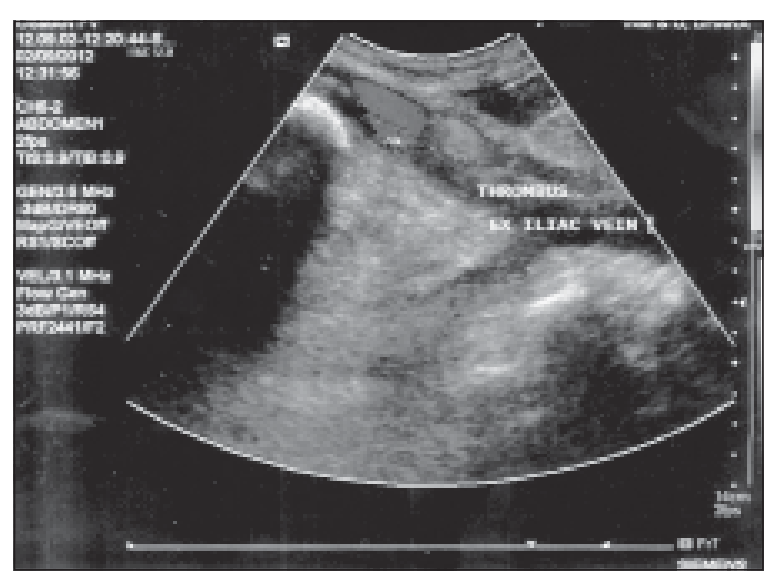

Fig :2 
Laboratory investigation revealed $\mathrm{Hb} 10 \mathrm{gm} / \mathrm{dl}$, WBC $7800 / \mathrm{mm} 3$, platelet count $370000 / \mathrm{mm} 3$, PCV $36 \%$,peripheral blood film was unremarkable. SGPT 56U/L(Normal <50U/L) SGOT 50U/L(Normal<45U/ L) Serum bilirubin $2.3 \mathrm{mg} / \mathrm{dl}$, Prothrombin time was prolonged(patient 21 second, control 12 second) Serum albumin was $2.8 \mathrm{gm} / \mathrm{dl}$.Ascitic fluid was transudative and negative for malignant cell . ADA was not significant (ascitic fluid) . APTT was 33 second (Normal 26-36 second) .D-dimers were $763 \mathrm{ng} / \mathrm{ml}$ (Normal <500ng/ ml). HbsAg Anti HBcIgM ,Anti HCV , AntiHAV and Anti HEV were negative . Plasma levels of protein C was6.3\% (Normal-70-140\%), Protein S was 28\% (Normal 60-130\%) and anti thrombin III was 64.4\%(Normal75-125\%) .Anti-phospholipid Ab(IgG and IgM ) were negative. Chest Xray was normal and trans thoracic echocardiography revealed thrombus in the right atrium and mild pericardial effusion but no evidence of constrictive pericarditis.Ultrasonography revealed mild hepatomegaly with thrombus in middle and left hepatic vein ,inferior vena cava , right atrium and common iliac vein. There was also moderate ascites. There was no splenomegaly or lymphadenopathy. Doppler study of abdominal vessels revealed thrombus in IVC and external iliac vein with intrahepatic venous occlusion and normal duplex study of portal vein(Fig $1 \& 2$ ). Endoscopy revealed early oesophageal varices with portal hypertensive gastropathy. Urine R/M/E was unremarkable and heat coagulation test was negative He was diagnosed as a case of acute budd chiari syndrome with protein $\mathrm{C}$, protein $\mathrm{S}$ and antithrombin III deficiency. Treatment was started with standard heparin and warfarin.

\section{Discussion:}

The Budd-Chiari syndrome occurs due to hepatic vein obstruction leading to hepatic congestion .Consequently portal hypertension ,ascites, reduction in hepatic blood flow and hepatic necrosis develops. Depending upon the speed of occlusion and extent of hepatic venous obstruction BCS may be classified as acute, subacute or chronic ${ }^{9}$. In acute BCS patient usually presents with rapidly progressive

severe upper abdominal pain, jaundice , elevated liver enzymes ,encephalopathy within 2-3 weeks(<4weeks). Patient may die due to hepatocellular failure. In this case patient presented acutely with similarly within 2 weeks symptom onset. On the other hand, chronic cases present over several months with enlargement of caudate lobe, protein rich ascitic fluid ,gastric varices, haemorrhoids , splenomegaly ,thickened obstructed vein wall with partial recanalization, portal vein involvement with venoportal cirrhosis ${ }^{9,10}$. Rahman et al reported a case in 2007 with above findings in Bangladesh ${ }^{11}$.

Ultrasonography with doppler study is often sufficient for diagnosis of BCS. Besides the level of obstruction these two investigation give clue whether BCS is acute or chronic. In acute case there may be intraluminal blood clot like in this case. On the other hand in chronic case there may be thickening of veins with or without clot inside due to long standing stasis which was present in Rahman et al. Case. Chronic phase may also show nonvisualization of occluded vein and formation of collateral veins within the liver or from the liver to left renal vein or pericardiophrenic vein, thrombosis of portal vein ${ }^{12}$. USG may sometimes helps to elucidate some secondary causes of hepatic venous obstruction from outside like mass lesion, lymph node, abscess, and cyst or within the lumen like parasitic mass leading to BCS. In this case we found no such lesion. Hepatic Venography, inferior venacavography,CT or MRI may sometimes required to diagnose site and extent of lesion in BCS.

BCS may be caused by various etiologies. Enhanced intravenous coagulation due to Protein C ,Protein S and Antithrombin III deficiency are well recognized to cause $\mathrm{BCS}^{13,14}$.In this case patient had severe deficiency of these factors (measured before starting anticoagulant ) which were responsible for clot formation inside hepatic veins and IVC .Genetic testing for mutated gene may identify whether these factor deficiency are hereditary or not but blood level less than 50\% normal suggest hereditary deficiencies. Anti Phospholipid antibody syndrome, paroxysmal nocturnal haemoglobinuria, DIC were excluded from history ,physical exam and laboratory investigations.Other common causes of BCS like membranous webs ,myeloproliferative syndrome(e.g. Polycythaemia vera), Behcet's disease ,Neoplasia were excluded. Patient gave no history of trauma ,infection or total parenteral nutrition that may give rise to BCS.

In our patient we started treatment with fractionated heparin (enoxaparin) with warfarin followed by only 
warfarin. He was also given prophylaxis for portal hypertension as there was portal hypertensive gastropathy with grade I oesophageal varices. Diuretics was given for ascites. His clinical condition was improving and he was on constant follow up schedule for evaluation of thrombus resolution.

Conclusion:

Budd chiari syndrome is associated with a number of hypercoagulable states . Very rarely combined protein $\mathrm{C}$,protein S and antithrombin III deficiency are found in Budd Chiari syndrome. High index of suspicion should be there to identify it and genetic study may be used to elucidate the cause. Whatever may be the cause standard protocol should be used to treat Budd Chiari syndrome with these factors deficiency.

\section{References:}

1. Janssen HLA, Garcia-Pagan JC, Eilas E., Mentha G, Hadengue A, Valla DC:Budd-Chiari syndrome: a review by an expert panel. J Hepatol 2003; 38, 364-371.

2. DeLeve LD, Valla DC, Garcia-Tsao G: Vascular disorders of the liver. Hepatology 2009; 49, 1729-1764.

3. Ludwig J, Hashimoto E, McGill DB, van Heerden JA: Classification of hepatic venous outflow obstruction: ambiguous terminology of the Budd-Chiari syndrome. Mayo Clin Proc 1990; 65(1):51-55.

4. Okuda K, Kage M, Shrestha SM: Proposal of a new nomenclature for Budd-Chiari syndrome: hepatic vein thrombosis versus thrombosis of the inferior vena cava at its hepatic portion. Hepatology 1998;28(5):1191-1198.
5. Valla DC: Primary Budd-Chiari syndrome. J Hepatol; 2009, 50, 195-203.

6. Slakey DP, Klein AS, Venbrux AC, Cameron JL. Budd-Chiari syndrome: Current management options. Ann Surg 2001; 233(4) : 522-527.

7. Ringe B, Lang H, Oldhafer KJ, Gebel M, Flemming P, Georgii A, et al. Which is the best surgery for Budd-Chiari syndrome: venous decompression or liver transplantation? A single-center experience with 50 patients. Hepatology 1995;21(5):13371344.

8. Halff G, Todo S, Tzakis A, Gordon R, Starzl T. Liver transplantation for Budd-Chiari syndrome. Ann Surg 1990;211:43-49.

9. Dang H, Thomas P, Tuan N, Membranous obstruction of hepatic venous flow ; tex Heart inst J 1995;22:320-323.

10. Harry LA, Juan-Carlos GP, Budd Chiari Syndrome, The new Eng J of Med 2004 ; 350:1906-1908.

11. Rahman MM,S Haque KMHS,Siddiqui MMR, Parvin T,Ahmed MK . Budd Chiari Syndrome : A case report.University Heart Journal 2007; 3(2):80-82

12. Blum U, Rossle M, Haag K, et al.Budd Chiari syndrome: technical, hemodynamic \& clinical results of treatment with transjugular intrahepatic potosystemic shunt.Radiology 1995;197:805-811.

13. Bourliere M, Le Treut YP, Arnoux D, Castellani P, Bordigoni L, Maillot A, Autoni M, Botta D, Pol B, Gauthier AP. Acute Budd-Chiari syndrome with hepatic failure and obstruction of the inferior vena cava as presenting manifestations of hereditary protein C deficiency. Gut1990; 31: 949-952

14. Das M, Carroll SF. Antithrombin III deficiency: An etiology of Budd-Chiari syndrome. Surgery1985; 97: 242-246 